\title{
Evaluating the Effect of Drying Methods on the Properties of a Water Base Drilling Mud
}

\author{
Akintola Abidemi Sarah", Arigbe Titi Ebidiseghabofa \\ Department of Petroleum Engineering, University of Ibadan, Ibadan, Nigeria \\ Email address: \\ demiabdul27@yahoo.com (A. A. Sarah) \\ ${ }^{*}$ Corresponding author \\ To cite this article: \\ Akintola Abidemi Sarah, Arigbe Titi Ebidiseghabofa. Evaluating the Effect of Drying Methods on the Properties of a Water Base Drilling \\ Mud. American Journal of Mechanical and Materials Engineering. Vol. 5, No. 1, 2021, pp. 18-22. doi: 10.11648/j.ajmme.20210501.14
}

Received: January 8, 2021; Accepted: January 21, 2021; Published: March 17, 2021

\begin{abstract}
It is important to understand the properties influencing the efficiency of a drilling fluid while drilling for oil and gas. As a result, drilling fluid must be designed in order to comply with three important requirements which are easy to use, cost effective and being environmentally friendly. Several studies have been carried out on the use of local materials as suitable substitute for imported additives. This study focuses on the use of starch processed from local cassava (Manihot esculenta Crant), (TME 419) using the process of wet milling and dried using three different methods namely: oven drying, direct heating and sun drying Due to this short coming resulting from the use of native starch, the starch was chemically modified using the process of esterification before being used as additive for treatment of the water-based drilling. The mud samples were prepared using Wyoming bentonite and distil water as the base fluid. Varying concentration of additives $(0.5,1.0$ and 1.5 g) were added to the different mud samples and the laboratory test carried out in accordance with the API Recommended Practice $13 \mathrm{~B}$ at varying temperatures $\left(30,50.70\right.$ and $\left.90^{\circ} \mathrm{C}\right)$. The various mud samples rheological properties was determined using a Fann35A rheometer and the filtration properties using a low -Temperature and High -Pressure API Filter Press at 100 psi with a 3.5" filter paper. The mud samples labelled labeled A, B and C were treated with oven dry, direct heat and sundry modified starches, respectively. While two control mud samples were prepared using low viscous Carboxymethyl cellulose for mud sample D and extra high viscous CMC in sample E. Although the Viscosity and fluid loss profiles result of the mud samples comparable performance with that of the commercial CMC's. However, mud samples treated with oven dried starches presented the best results in their rheological as well as fluid loss properties
\end{abstract}

Keywords: Cassava Starch, Carboxymethyl Cellulose, Fluid Loss, Rheology, Esterification

\section{Introduction}

Since it first came into use in the USA, drilling fluid has gone through major technological evolution from a simple mixture of water and clays, to complex mixtures of various specific organic and inorganic products used nowadays. Drilling fluid is said to represent about 15 to $18 \%$ of the total cost of an oil well drilling. Also the type of formation and its characteristics plays an important role during the selection of the type of drilling fluid to be used. Hence to ensure proper functionality of drilling mud, adequate understanding of these factors is key. Additives play significant role in oil and gas drilling operations, different additives are used to enhance the base fluid in order to enable the drilling fluid achieve its different functions such as: cleaning the well, cooling and lubricating the bit, suspension of the cuttings preventing caving, forming a thin impermeable cake round the wellbore tool, transfer the hydraulic power and carry the drilled cutting from the bottom and releasing them at the surface. Starch is used by plants as source of carbon and energy Smith [1], and starch synthesized from plants are divided into 2 namely: Amylopectin and amylose. Amylopectin is a highly branched polymer of glucose found in plants, it is insoluble in water. Amylose has a linear structure of glucose chain found in plants, is soluble in water. The amylopectin and amylose content of starch affect certain physiochemical properties such as morphology, size, composition, crystallinity, swelling capacity and solubility of starch granules. Other characteristics associated with the starch granule such as form, surface type and phosphate 
groups influence the starch's properties and uses Smith [1].

Starch can be applied in the oil and gas industry as a viscosifier and fluid loss additive in drilling fluids. Ismail and Abdul Kadir [2], examined the use of corn starch in comparison to PAC and HEC, their results, show that corn starch is one of the natural resource which have a high potential as mud additive for drilling wells because of its high biodegradability. Amanullah and $\mathrm{Yu}$ [3] also showed the superior characteristics of the Corn-based Starches for Oil Field Application. Akintunde and Tunde-Akintunde [4] investigated the effect of drying methods on cassava starch extract properties (such as swelling capacity, water binding capacity, solubility and pasting properties), using two drying methods (sun and oven drying at $40^{\circ} \mathrm{C}$ ), from the result, he concluded that the sun-dried samples gave lower values for most of the properties than oven dried samples which might be attributed to the lower drying temperature involved. Akintola and Isehunwa [5] examined the effect of temperature and aging on water base mud treated with starches prepared from maize and cassava. From their result, they observed that the effect of aging resulted in the plastic viscosity of starches treated with maize starch to decrease more than that of cassava starch and the rheological properties of water based drilling fluids treated with the maize and cassava starches decreases with increase in temperature. Amel [6] investigated the use of potato starch as a viscosifier and fluid losses agent in drilling fluid. The study shows that potato starch could enhance gel strength at low $\mathrm{pH}$ (approximately 8.6) and viscosifir at high $\mathrm{pH}$ mud (approximately 10.8). The optimum $\mathrm{NaOH}$ concentration was between (2-6) lb./bbl with a reserval in the value of $\mathrm{pH}$ and plastic viscosity if more than that concentration was used. His results proved that rheological properties of potato starch mud increased when $\mathrm{pH}$ of drilling fluid is increased.

Due to its various short comings, starch has to be modified to overcome the problem of degradation at higher temperatures. Various methods of modifications such as chemical, physical, and thermal treatment are available. Talukdar and Gogoi, [7] used the Pre-Gelatinized Starch (PGS) as the fluid loss control agent in the Non Damaging Drilling Fluid (NDDF) and demonstrated the effectiveness of the use of formaldehyde (Bactericide) as the biodegradation control agent in the Non Damaging Drilling Fluid (NDDF). The method of chemical modification via Carboxymethylation was used in this study. Carboxymethyl starch (CMS) is obtained by chemically modifying native starch using monochloroacetic acid, it was first made in 1924 by the reaction of starch in an alkaline solution ( $40 \%$ aqueous $\mathrm{NaOH}$ ) with sodium monochloroacetate. Carboxymethyl starch are polymers easily to handle. Contact of CMS with the eyes may cause mild irritation. Health and flammability hazards are slight. There are no known carcinogenic effects and no known medical conditions that could be aggravated by exposure. Carboxymethyl starch can be prepared from variety of starches such as corn (Khalil et al., [8] wheat (Thewlis, [9]), potato (Kuniak et al., [10]) Szathmary et al., [11], high-amylose corn (Solan et al., [12]) and related sources such as cellulose-starch mixture (Sanir and Bochow, [13]) and corn starch waste (Yamauchi and Sasaki. [14]. Carboxymethyl starch (CMS) is a natural starch derivative. Khalil, [8] examined the reaction of maize starch with monochloroacetic acid in presence of sodium hydroxide under variety of conditions, in order to ascertain the chemical factors which affect the carboxymethylation reaction of starch. His results indicated that starch: water ratio of $1: 2.5$ constitutes the optimal material to liquor ratio also increasing sodium hydroxide concentration up to $8 \mathrm{~N}$ causes significant enhancement the yield of carboxymethyl starch. It was found that the highest Degree of substitution is achieved with isopropyl alcohol and the least with water. The Degree of substitution follows the order: isopropanol $>$ cyclohexane $>$ dimethyl formamide $>$ methanol $>$ acetone $>$ water. Isopropanol: water mixture $(80: 20)$ constitutes the most favorable medium for the carboxymethylation reaction under the conditions used. Shinde,[15] investigated the reaction conditions such as reaction time, ph of the reaction medium and reaction temperature for the highest yield of Carboxymethyl starch. He concluded that reaction time of 90 minutes at ph of 10.5 and a temperature of $70^{\circ} \mathrm{C}$ results give the maximum yield of carboxymethyl starch. Minaev, [16], investigated the synthesis of Carboxymethyl Starch for increasing drilling mud quality in drilling oil and gas wells, while varying the main parameters of carboxymethylation, and concluded that the conditions such as temperature and reaction time, amount of water, as well as ratio of $\mathrm{NaOH}$ to monochloracetic acid define the characteristics of carboxymethyl starch. With the use of isopropanol as solvent presenting the best filtration loss properties. Aliyu et al [17] examined the effectiveness of the use of acetylated or carboxymethylated starches from cassava and maize for drilling HPHT well. Their results shows that the mud samples exhibited filtrate volumes and filtrate losses within the American Petroleum Institute specification. The objective of this paper is to present a laboratory investigation on the effects of drying methods of starch on the properties of on water based drilling fluid.

\section{Materials and Method}

\subsection{Preparation of Starch from Native Cassava Tubers}

Materials: Mechanical grinder. Peeler, Gibson SS -10 Touch Vibratory Shaker 8 inch sieve shaker, Kitchen knife, Distil water, Scanfrost Gas Cooker model 5402 B, Middle size Bowl. One kilogram of Freshly harvested cassava tubers (TME 419) were purchased from a local farm at Atiba local Government Area, Oyo State.

Procedure: The cassava tubers were washed thoroughly and peeled using a peeler before it was diced into smaller proportions using a kitchen knife. The diced tuber was grinded to form a paste using a mechanical grinder. The paste, further diluted with distil water before draining through the Gibson SS -10 Touch Vibratory Shaker 8 inch sieve shaker.

The extracted starch mixture was allowed to stand for 
about 3 hours, before the water was drained and the starch (at the bottom) recovered. The starch obtained was shared into 3 parts they were dried separately by drying, Direct heating and Sun drying were used to dry each part. A part of the starch sample labelled Sample A, was put inside a flat tray and placed inside an oven (Scanfrost Gas Cooker model 5402 B) at temperature of $40^{\circ} \mathrm{C}$, to obtain the Oven dried starch. Another starch (Sample B), was put on a flat tray and placed on direct heat from a gas burner (Scanfrost 4 burner) to get the direct heated starch while the last starch sample $\mathrm{C}$ was placed on a flat tray and left outside to the sun dry, this was the Sun dry method.

\subsection{Preparation of Carboxymethyl Starch}

Materials: The materials used are native starches (Sample A, B and C), Weighing balance, Spatula, Beakers, Three neck round bottom flask, Conical flasks, Measuring cylinder, Thermometer, Heater with a magnetic stirrer, Vacuum pump, Sodium monochloroacetate (SMCA, Sigma-Aldrich), isopropanol. Sodium hydroxide acetic acid, All the chemicals used were all of Analytical grade.

Preparation:

The process of preparing Carboxymethyl starch was carried out using the method of Khalil et al [8] with slight modification.

\subsection{Mud Preparation and Experimental Procedures}

\section{Materials:}

Distil water (350ml) Bentonitic clay, Lv-Carboxyl Methyl Cellulose (CMC), Hv-Carboxyl Methyl Cellulose (Hv-CMC) were obtained from Mi- Swaco. Rivers State, Nigeria.

Apparatus:

The digital weighing balance, mixer cup, Hamilton mixer, mud mixer machine, thermometer, Gibson SS -10 Touch Vibratory Shaker 8 inch sieve shaker, Fann 35A rheometer, API Filter Press, measuring cylinder were all from the department of Petroleum Engineering Laboratory, University of Ibadan, according to the API Recommended Practice 13B [18].

Procedure:

The water-based drilling fluid was prepared using $22.5 \mathrm{~g}$ of bentonite added to $350 \mathrm{~mL}$ of distil water, mixed thoroughly using a Hamilton mixer to obtain a homogenous solution and poured into the labelled cups. Thirty-six samples were formulated with all samples of synthesized starch and twelve samples each were formulated with low viscous carboxymethyl Cellulose (CMC) and extra high viscous carboxymethyl cellulose (CMC).

The Fann 35A dial readings at $600 \mathrm{rpm}$ and $300 \mathrm{rpm}$ were recorded for each mud sample. The Apparent viscosity, Plastic viscosity and Yield point and were calculated by the application of the equations 1,2 and 3 , respectively.

$$
\begin{gathered}
A v=\frac{\theta_{600}}{2.0} \\
P v=\theta_{600}-\theta_{300} \\
Y p=\theta_{300}-\left(\theta_{600}-\theta_{300}\right)
\end{gathered}
$$

\section{Result and Discussions}

\subsection{Rheological Test Values for the Different Samples at Varying Temperatures}

As the concentration of carboxymethyl starch increases irrespective of the drying method, the rheological parameters (plastic viscosity, apparent viscosity and yield point) increases. Also as temperatures increases the rheological properties increase. The oven drying method show the best rheological properties followed by the directly heated and then the sun dry. From the results obtained and shown in the figures 1, 2 and 3 for the apparent viscosity, plastic viscosity and yield point, respectively for $0.5 \mathrm{~g}$ of the additives.

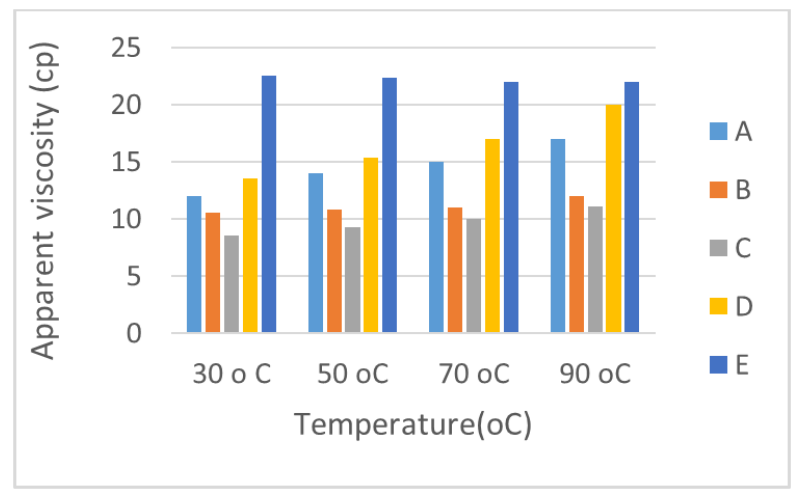

Figure 1. Apparent viscosity (cp) for 0.5g Mud Samples against Temperature $\left({ }^{\circ} \mathrm{C}\right)$.

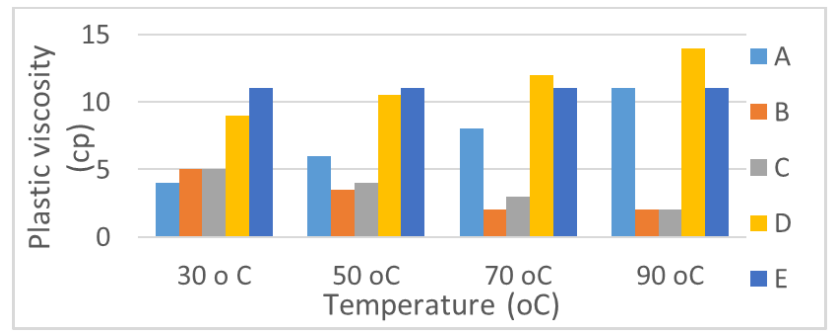

Figure 2. Plastic viscosity (cp) for 0.5g Mud Samples against Temperature $\left({ }^{\circ} \mathrm{C}\right)$.

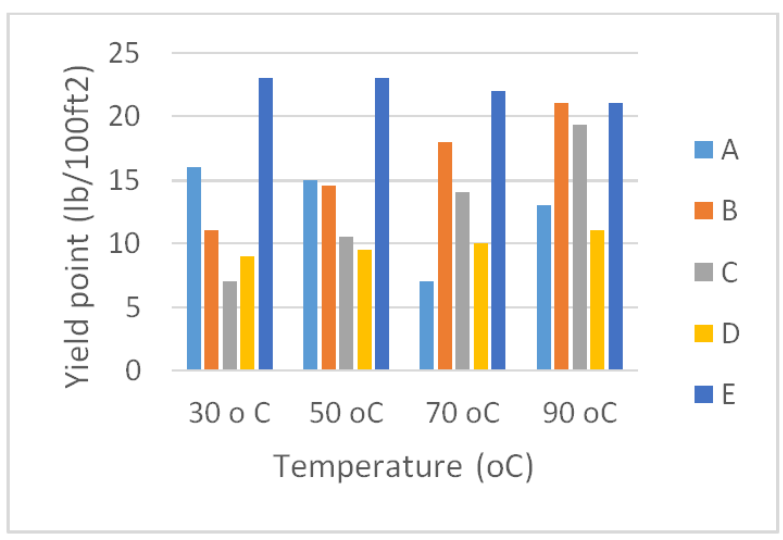

Figure 3. Yield point (lb/100ft $)$ for $0.5 g$ Mud Samples against Temperature $\left({ }^{\circ} \mathrm{C}\right)$.

While the figures 4, 5 and 6 shows the apparent viscosity, plastic viscosity and yield point, respectively for $1.0 \mathrm{~g}$ of the additives with increase in temperature for each mud sample. 


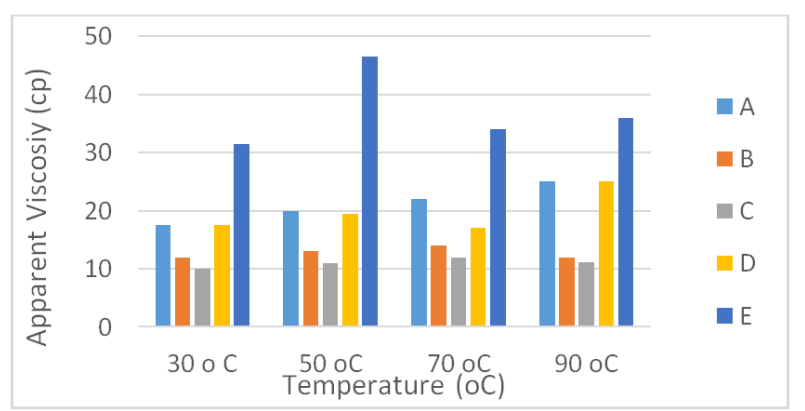

Figure 4. Apparent viscosity (cp) for $1.0 \mathrm{~g}$ Mud Samples against Temperature $\left({ }^{\circ} \mathrm{C}\right)$.

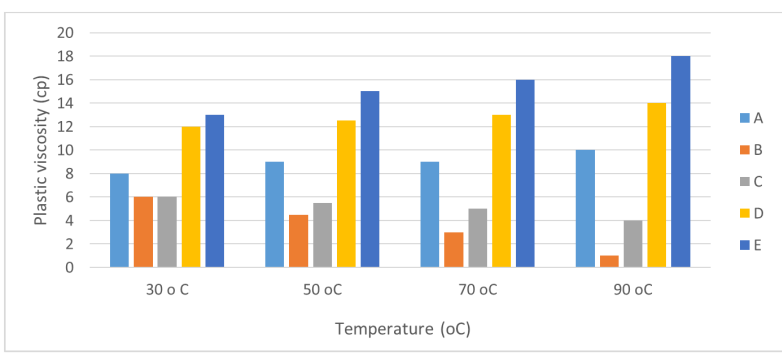

Figure 5. Plastic viscosity (cp) for 1.0g Mud Samples against Temperature $\left({ }^{\circ} \mathrm{C}\right)$.

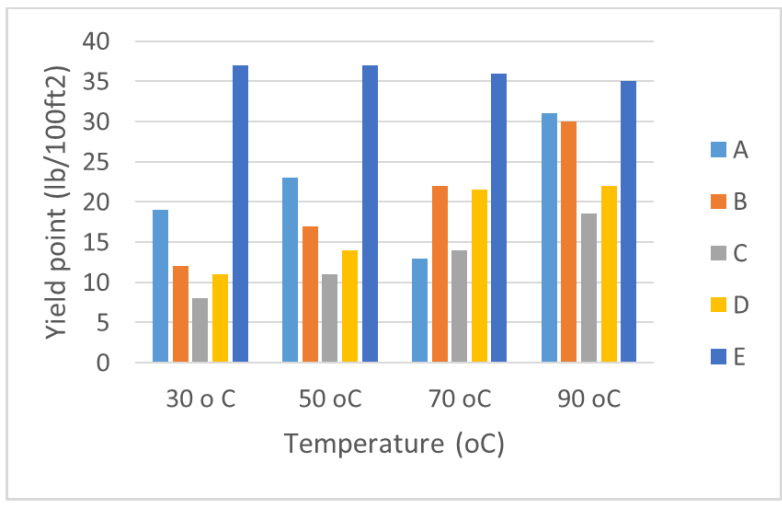

Figure 6. Yield point (lb/100ft $\left.{ }^{2}\right)$ for $1.2 \mathrm{~g}$ Mud Samples against Temperature $\left({ }^{\circ} \mathrm{C}\right)$.

Finally the figures 7,8 and 9 present the apparent viscosity, plastic viscosity and yield point, respectively for $1.5 \mathrm{~g}$ of the additives with increase in temperature for each mud sample

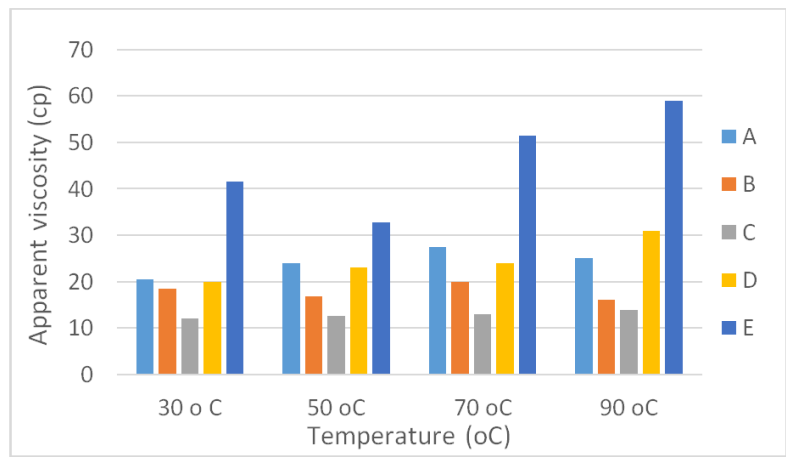

Figure 7. Apparent viscosity (cp) for $1.5 \mathrm{~g}$ Mud Samples against Temperature $\left({ }^{\circ} \mathrm{C}\right)$.

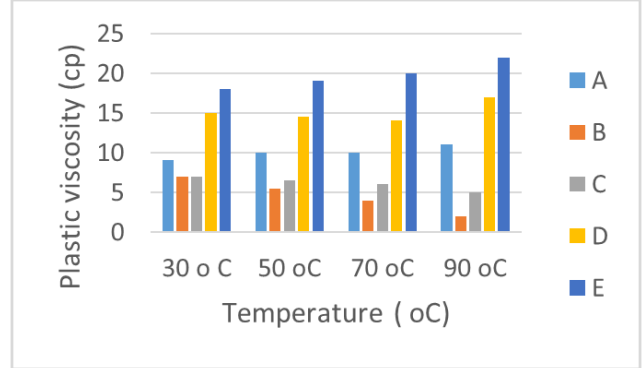

Figure 8. Plastic viscosity (cp) for $1.5 \mathrm{~g}$ Mud Samples against Temperature $\left({ }^{\circ} \mathrm{C}\right.$ ).

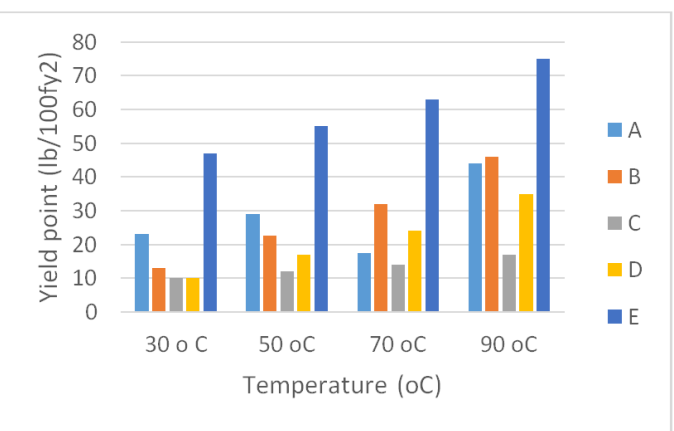

Figure 9. Yield point $\left(\mathrm{lb} / 100 f \mathrm{ft}^{2}\right)$ for $1.5 \mathrm{~g}$ Mud Samples against Temperature $\left({ }^{\circ} \mathrm{C}\right)$.

\subsection{Filtration Loss Test for the Different Mud Samples at Different Temperature}

The results below shows the filtration loss for each samples From Figures as the temperature increases for each drying method less fluid is expelled from the mud samples. The oven drying method show the best filtration loss properties as less fluid is expelled from followed by the directly heated and finally the sun dried sample.

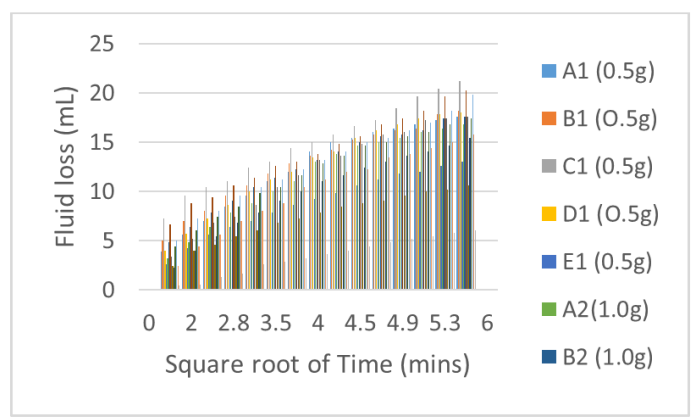

Figure 10. Filtration loss $(\mathrm{mL})$ for samples at $30^{\circ} \mathrm{C}$.

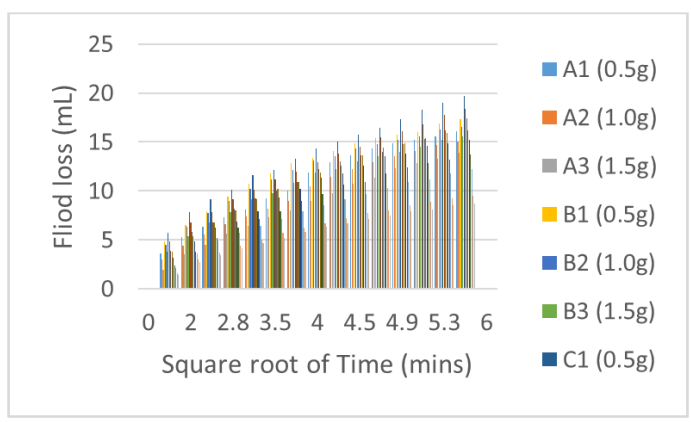

Figure 11. Filtration loss $(\mathrm{mL})$ for samples at $50^{\circ} \mathrm{C}$. 


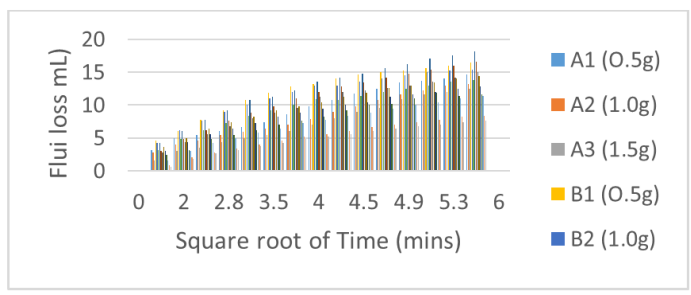

Figure 12. Filtration loss $(\mathrm{mL})$ for samples at $70^{\circ} \mathrm{C}$.

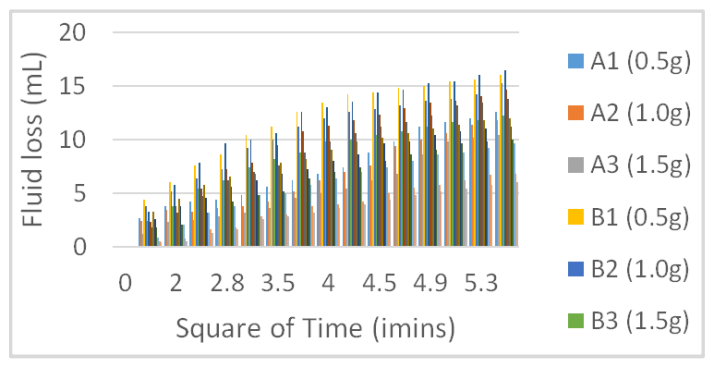

Figure 13. Filtration loss $(\mathrm{mL})$ for samples at $100^{\circ} \mathrm{C}$.

\section{Conclusion}

From the result obtained at the cause of this, the rheological and filtration properties of different samples of drilling fluid shows that irrespective of the method used for drying, as concentration of the Carboxymethyl starch increases, the rheological properties increase and less fluid is loss from the mud samples. The oven dried carboxymethyl starches possessed close similarities to the low viscous carboxymethyl cellulose used in the oil and gas industry. In conclusion, the use of oven in drying the starch granules is the best option relative to direct heating and sun drying, this method allows for synthesized carboxymethyl starch possess the best rheological properties and filtration loss properties.

\section{References}

[1] Smith, Alison M. (2001). "The Biosynthesis of Starch Granules". Biomacromolecules. 2 (2): 335-41. doi: 10.1021/bm000133c. PMID 11749190.

[2] Ismail, I., and Abdul Kadir, A. A. (1998) "The Importance of Implementing Proper Mixing Procedures in The Preparation of HEC and Corn Starch Mixtures for Controlling Fluid Loss". Proceedings of International Conference on Mixing and Crystallization. April 22-25. Tioman Island, Malaysia: UTM, 1-8.

[3] Amanullah, M., and Yu, L. (2004). "Superior Cornbased Starches for Oil Field Application". Proceedings of the 4th
International Crop Science Congress. September 26 - October 1. Brisbane, Australia: ICSC, 1-6.

[4] Akintunde B. O. and Tunde-Akintunde T. Y. (2013): Effect Of Drying Method And Variety On Quality Of Cassava Starch Extracts Vol. 13 No. 5.

[5] Akintola,. S. A., and. Isehunwa S. O, (2015): Temperature and Time-Dependent Behaviour of a Water Base Mud Treated with Maize (Zea mays) and Cassava (Manihot esculanta) Starches. Journal of Scientific Research and Reports. 5 (7), pp. 591-59.

[6] Subrata Gogoi and Prasenjit Talukdar (2015): Effect and Optimization of Bactericide to control Biodegradation in non damaging drilling fluid (NDDF): International Journal of Scientific Research 6 (10): 6788-6794.

[7] Amel Habeeb Assi (2018): Potato Starch for Enhancing the Properties of the Drilling Fluids Iraqi Journal of Chemical and Petroleum. Engineering Vol. 19 No. 3 33-40.

[8] Khalil, M. I., Hashem, A. and Hebeish, A. 1990. Carboxymethylation of maize starch. Starch/Starke 42 (2): 60-63.

[9] Thewlis, B. H. (1969). Starke, 21, 21.

[10] Kuniak, L., Kodet, J., Nevydal, J., Frimm, R. and Zemek, J. (1985). Czech CS, 219, 107.

[11] Szathmary, E., Petery, I. and Land, B. (1970). Hung Teljes, $7-$ 08 .

[12] Sloan, J. W., Mehltretter, C. I. and Senti, R. F. (1962). Carboxymethyl high amylose starch. Journal of Chemical Engineering Data 7 (1): 156-158.

[13] Sanir, J. D. and Bochow, K. (1983). Ger. (east), DD 158, 403

[14] Yamauchi, T., and Sasaki, M. (1992). Method for production of a corn milling residue carboxymethyl ether salt, United States Patent, 5166336.

[15] Shinde V. V., (2005). Production Kinetics and Functional Properties of Carboxymethyl.

[16] Minaev, K M, Martynova, D O., Zakharov, A S, Sagitov, R R, Ber, A A and Ulyanova, O S (2016): Synthesis of Carboxymethyl Starch for increasing drilling mud quality in drilling oil and gas wells, IOP Conference Series: Earth and Environmental Science, 10.1088/1755-1315/43/1/012071, 43, (012071).

[17] Aliyu Adebayo Sulaimon, Sarah Abidemi Akintola, Mohd Adam Bin Mohd Johari and Sunday Oloruntoba Isehunwa (2020): Evaluation of drilling muds enhanced with modified starch for HPHT well applications. Journal of Petroleum Exploration and Production Technology.

[18] API 13A, Specification for Drilling Fluids - Specifications and Testing. API Specification 13A, $18^{\text {th }}$ Edition., 2010. 